\title{
Cloud Computing Technologies Adoption in Higher Education Institutes During COVID-19 Pandemic: Case Study
}

\author{
Mohammed Yousif Shakor ${ }^{1}$, Nigar M. Shafiq Surameery ${ }^{2 *}$ \\ ${ }^{1}$ Department of English, College of Education, University of Garmian, Kalar, Kurdistan Region, Iraq \\ ${ }^{2}$ Information Technology Department, College of Computer and Information Technology, University of Garmian, Kalar, Kurdistan Region, Iraq
}

Received 24 July 2021; revised 10 August 2021;

accepted 01 September 2021; available online 01 October 2021

doi: $10.24271 /$ psr.31

\begin{abstract}
The global spread of Covid-19 has enhanced the adoption of virtual education and the use of technology in order to reduce the risk of contagion. Recently, the academics have turn out to be more technology-orientated and the educational establishments continue to seek opportunities in order to adopt an environment where all researchers could have access to high-quality scientific resources at anytime and anywhere in the world. Cloud computing is a model, which provides the users with services and application software on-demand, using the Internet. While the use of cloud computing applications is growing, there are ongoing research challenges related to guaranteeing security, privacy and the integration of the cloud applications. To the extent of our knowledge, the present study is the first from this type to thoroughly present the impacts of the COVID-19 pandemic on cloud computing environment in higher education institutions in Iraqi universities. This study will critically analysis the views of the faculty staff and researchers in Iraqi universities on cloud computing. It also tries to take a quick look at how Iraqi university staff responded to the epidemic in terms of research activities. The results show that about $99 \%$ of the respondents considered the cloud applications to have great role in encouraging the research works in their institutes. Concerning the benefits of cloud services, the availability and saving cost were selected as most important factors that encouraging the adoption of cloud services. On the other hand, issues related to performance, lack of user control were selected as major problems in applying cloud services in Iraqi institutions. Finally, it can be concluding that reducing the risks of the security, authorization, control and providing better performance of cloud services can enhance the use of cloud applications by researchers at Iraqi universities.
\end{abstract}

\section{(C) 2021 Production by the University of Garmian. This is an open access article under the LICENSE}

https://creativecommons.org/licenses/by-nc/4.0/

Keywords: Cloud Computing Application; Cloud Services; COVID-19; E-Learning; Virtual learning.

\section{Introduction}

The pandemic of COVID-19 has a certain impact on the life style worldwide. To the date of working on the present study, the virus has infected many countries around the globe. With the increasing number of infections, most countries have started to take this outbreak seriously. The existing cloud applications enabled communication between the university staffs with a lower hindrance and it was found to be a method that challenged our traditional approach in the higher education institutes. The higher education organizations affirm the use of modern teaching tools and techniques especially when education system has been changed from being teacher-centered to learner-centered in most

* Corresponding author

E-mail address: nigar.mahmoud@garmian.edu.krd (Instructor).

Peer-reviewed under the responsibility of the University of Garmian. present systems. Nowadays, the students as well as the educational staffs, pay more and more attention to technology, this paved the way for introducing new methods of teaching such as online learning, electronic learning and research collaboration. Cloud computing is a model of delivering services, frameworks and applications on-demand over the Internet with pay-as-you-go cost structure. It provides more kinds of academic solutions.

Recently, many academic institutes are exploring new technologies for active research methodology. One of the most important techniques that can increase the efficiency of education is the cloud. With the support of cloud computing, users can use the platform and applications on campus or off campus according to the needs of the institution, or use a combination of the two ${ }^{[1]}$. The cloud computing differs from traditional hosting concept where used Internet to host applications and/or data. With the use of the Internet, A client can access these services anytime and from any zone ${ }^{[2]}$. Therefore, cloud-computing resources must be easily accessible, secure, sharing capabilities, compatibility and 
availability. It also provides a high degree of security for preventing any loss of sensitive data. However, If any data loss occurs, it can be easily restored ${ }^{[3]}$.

Several big firms such as IBM, Amazon, Google, and Microsoft have commenced to offer various cloud services to their users ${ }^{[4]}$. Therefore, the cloud computing is the best option to be used for educational purposes, especially when budgets are short in order to effectively run its information system without spending more money to buy computers and network equipment ${ }^{[5]}$. Moreover, the dynamic optimization of the shared data and applications among the users is realized through the cloud. For instance, since the cloud computing resources are allocated to costumers based on their time zones, therefore, an Asian user can be allocated with the same resources (such as email) according to his/her time zone $^{[6]}$.

Finally, cloud computing is the next stage of Internet usage development to be adopted by higher education institutions. This is because of its ability to offer the faculty staffs as well as the students the essential instruments, by sharing the services related to the IT in the cloud ${ }^{[7]}$.

The paper is organized as follows: In Section 2, literature review is discussed. Section 3 describes the cloud computing and its services. Section 4 discusses the adoption of cloud technology in education. Section 5 describes Iraq universities as case study. Section 6 presents the results and the last section 7 concludes the study and the main ideas for future work.

\section{Literature Review}

The impact of the COVID-19 pandemic on the cloud computing environment came from transferring a lot of application services and storing data to it. As academic institutions began to apply the principles of distance education and holding meetings and conferences via cloud computing services ${ }^{[8]}$.

COVID-19 pandemic has forced governments and their institutions to reassess how they use information systems and expand the use of technology to mitigate many of the impacts of the spread of the virus in various educational and research sectors ${ }^{[9]}$. Cloud computing technology has changed the way the teachers, educators and higher education institutions work. Universities must know their needs in terms of administration and scientific application and integrate their frameworks accordingly [10].

Many researches about the pros and the utilization of cloud computing in education have been conducted. Ali A. and Huma A. ${ }^{[11]}$ proposed a cloud computing application model, in which teachers can share course materials on the cloud, and students can use the model to get updates about materials, exams, homework and many things. The cloud application solves various mechanical problems encountered in the daily work of higher educational institutions ${ }^{[12]}$. Aishwarya S. et al. ${ }^{[13]}$ proposed an architecture that provide a way to share courses and educational progress between countries. Kenndy N. et al.[7] Conclude that, the most important barriers to the use of cloud computing are concerns about the reliability of Cloud Service Providers (CSP), security concerns and confidentiality of data. Moreover, Asgarali B. and Bahman A. ${ }^{[14]}$ recommended that the CSP should be particularly involved in providing cloud-based learning to improve the education situation in the poor countries in Asia and Africa. However, the results of the study carried out by
Muhammad A. indicate the lack of studies in adopting cloud computing applications in higher education institutions ${ }^{[15]}$.

Finally, this paper illustrates how the cloud computing application will provide and adopting these virtual services in higher education institutes. Additionally, the present study seeks to address the effect of COVID-19 outbreak on cloud computing environment.

\section{Cloud Computing}

Cloud computing represents one of the common types of Internetbased computing which can provide computers and other devices with shared computing resources and data as needed. It represents a model that enables users to access a shared configurable computing resource pool on demand and quickly configure and release with minimal management workload ${ }^{[16]}$. The cloud computing and the storage solutions can provide the institutions and users with various functions. They can store and process data in private or third-party data centers distributed over the world [17]. Furthermore, Cloud computing can provide different value proposition from the traditional enterprise IT environment. It can provide economies of scale by implementing a way to utilize virtualization and aggregate computing resources ${ }^{[18]}$. Cloud computing includes two parts: the CSP that provides cloud services and the "cloud users" that represented by organizations or individuals who accessing the provided cloud services. Institutions with weak financial status and limited human resources can own a large amount of computing equipment at low cost. Therefore, cloud users can immediately have the storage or computing power they need without worrying about hardware ${ }^{[19]}$. Some major examples of cloud computing services include Amazon Web Services (AWS), Google Cloud, Microsoft Azure, and Apple iCloud. The services offered by cloud providers can be classified into three various levels according to the National Institute of Standards and Technology (NIST) as shown in Figure 1 .

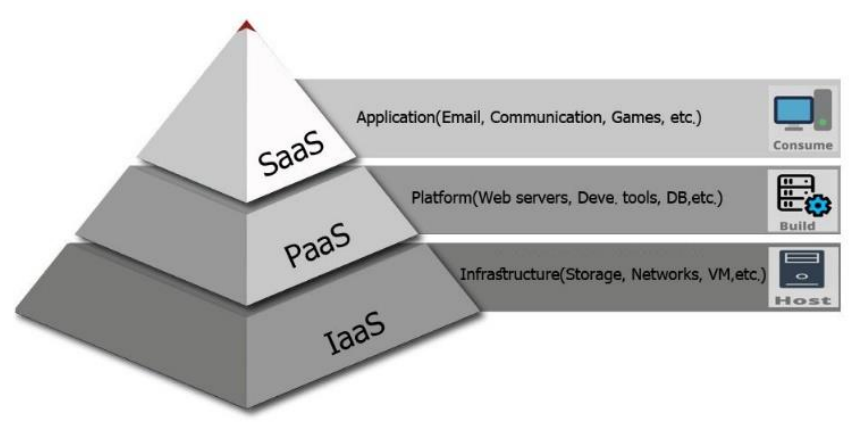

Figure 1: Cloud Services

A. Software as a Service (SaaS): These types of applications are usually designed for end users and delivered over the network. Applications or software stores on web-cloud, instead of installing and storing it on our own computer. SaaS is much more efficient for academic staff because it can access applications on any type of device (such as laptops, smartphones, tablets or other web-enabled devices) anytime and anywhere ${ }^{[1]}$. There are many available examples of SaaS providers companies such as Google, Salesforce, Microsoft and others $^{[3]}$. 
B. Platform as a Service (PaaS): Is a collection of developed tools and services that used to code and deploy applications quickly and efficiently. Academic institutions and government agencies can develop new applications or services in the platform-independent cloud, well as providing them to the users widely through the Internet.

C. Infrastructure as a Service (IaaS): It is an instant computing infrastructure that can be configured and managed via the Internet. Products provided through this model include remote delivery (via the Internet) of complete computer infrastructure (such as virtual computers, servers, storage devices, etc.) ${ }^{[20]}$. The virtual machine (VM) resources of IaaS are rented from cloud providers to cloud customers ${ }^{[21]}$. There are many available examples of IaaS providers such as Amazon Web Services (AWS), Microsoft Azure, Digital Ocean, and Google Compute Engine (GCE).

\section{Usage of cloud computing in education}

In today's world, the internet is working like a daily handy tool for users, where they can access their data and information easily. Cloud computing can be used to access the data and the applications online. Therefore, the amount of the storage in the device has not taken in to account since that everything is being stored in the provided cloud [3]. Many educational organizations have begun using cloud computing by outsourcing their student email provision. They also began their movement to use low level cloud services such as data storage. Cloud computing is additionally emerged in the educational sector for facilitating learning administration frameworks by hosting of learning management systems (LMSs), such as Moodle and Blackboard, within the cloud ${ }^{[22]}$. In addition, most of the educational organizations outsource the providers of the LMSs because of the costs problem associated with the foundation and maintenance of such frameworks ${ }^{[23]}$. Cloud computing is often associated with electronic-learning (e-learning) and mobile-learning (mlearning). The e-learning solutions, which is taking in arrangements run from commercial to open-source, has been adopted at different education sectors with different instruction levels including preparing for organizations, lifelong learning and in the scholarly units ${ }^{[24]}$. Consequently, academics can use the elearning systems to manage the courses and evaluate the assignments as well as communicating for their research purposes. The cloud deployment model is related to the configuration of the environment, which can be separated by parameters such as the size of deployment infrastructure, the accessibility, and the proprietorship of infrastructure. The type of cloud deployment will vary, depending on who controls the cloud infrastructure resources and its location.

To make the most utilize of this computing paradigm, academic institutions should adopt a deployment model that can be convenient it best. To select the appropriate one, they will require to take into consideration your computing, networking and storage requirements, available resources, and their objectives, as well as the advantages and disadvantages of cloud deployment models.

There are four deployment models for cloud computing: private, public, hybrid and community as shown in Figure 2. The private cloud managed and operated by single academic institution. It is also known as local or internal cloud. Its Infrastructure managed by only one institution and provides consumers who belong to the same institution that owns the cloud with limited access to their resources and services ${ }^{[25]}$. The public cloud may be purchased by one institution or some combinations of them. It is also known as multi-tenant cloud. In public cloud, resources are shared between users and the Pay for what you use is a popular and attractive sales tool for public cloud providers [25][26]. The third type is "hybrid cloud" which is a blend of (private and public) cloud ${ }^{[26]}$. Finally, the Community cloud term represents a special-purpose cloud environment organized and managed by the number of institutes engaging in the same domain.

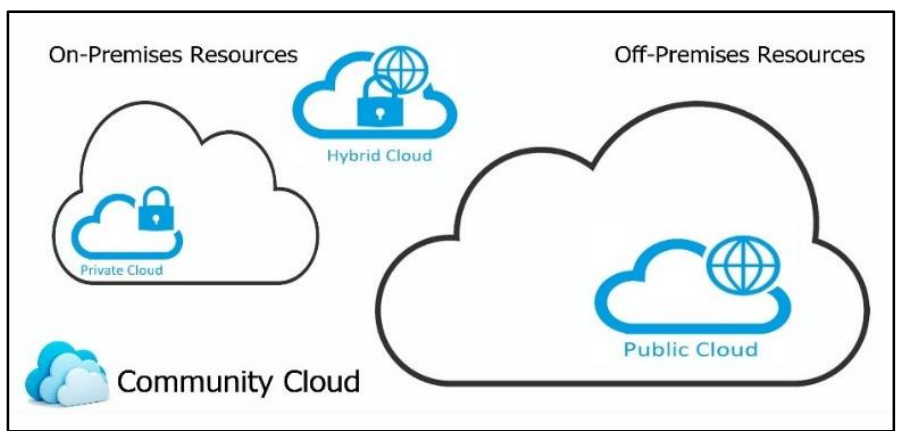

Figure 2: Cloud deployment models

\section{Iraqi Universities as the case study}

As it is clear in the literature review section, there are large numbers of research works related to the use of cloud computing application in the educational institutions during COVID-19 outbreak. In contrast, the present study critically examines the perception of the cloud computing by the university staffs such as the instructors and researchers in Iraqi Universities.

Further, it attempts to provide a quick glance of how Iraqi university staffs have responded to this pandemic in terms of their research activities. For the research purpose, Staffs who may have idea about the cloud were chosen, in total 319 persons were participate in this study.

As shown in Figures 3, 4, and 5, the numbers of participants were dominant from bachelor, Master and Ph.D, 61, 132 and 126 respectively. 151 males and 168 females participate in this study. 260 of the participants were members of public Iraqi universities while 59 of them were from private universities. As shown in Figure 6 , the rate of using cloud computing apps was $93 \%$, this is because 297 out of the 319 participants said that are using cloud computing apps and only 22 out of the 319 participants said that it would not use this solution before. According to the results in Figure 7 , it is clear that most of the participant agree with the ideas that the cloud computing offers the opportunity for increasing the efficiency and facilitate the communications among the users as well as facilitating the provision of scientific resources. However, only $7 \%$ of the participants strongly disagree, and ignoring the role of the cloud computing apps on facilitating the previous activities. The vast majority of the participant responded positively to the question - rating the role of cloud computing applications in encouraging the researchers in the Iraqi institutes and only $1 \%$ said that it would not have any roles for encouraging the researchers in their institutes. See Figure 8. 


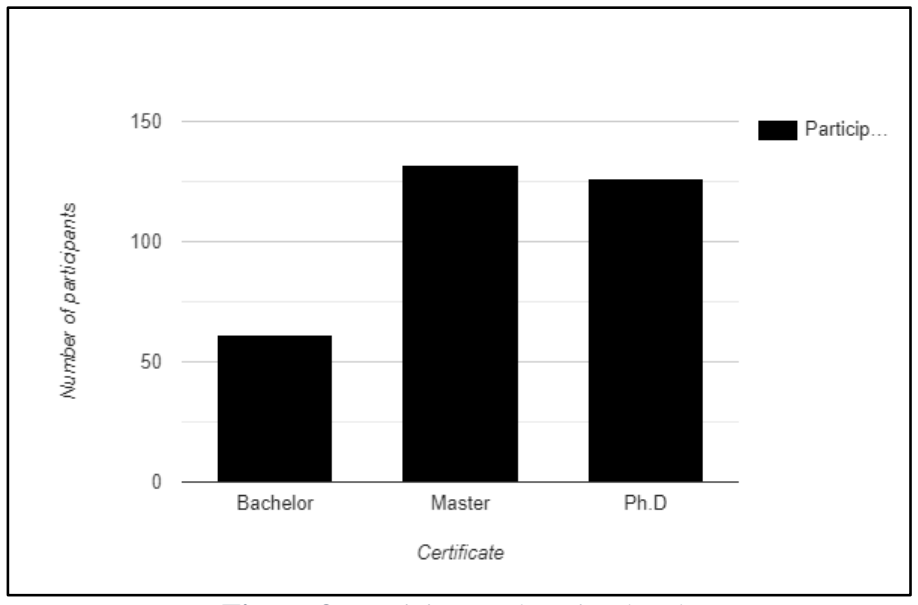

Figure 3: Participant education level

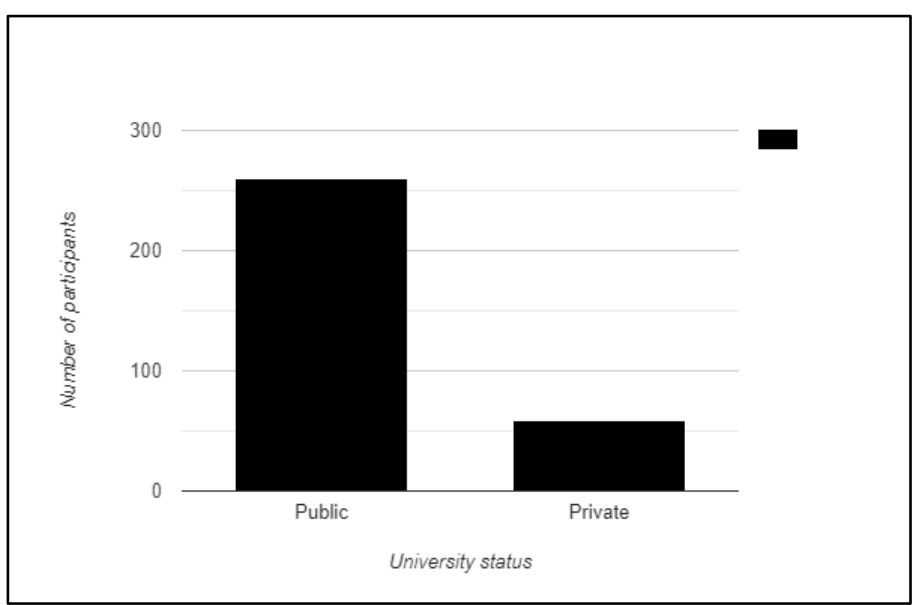

Figure 5: Participant university status

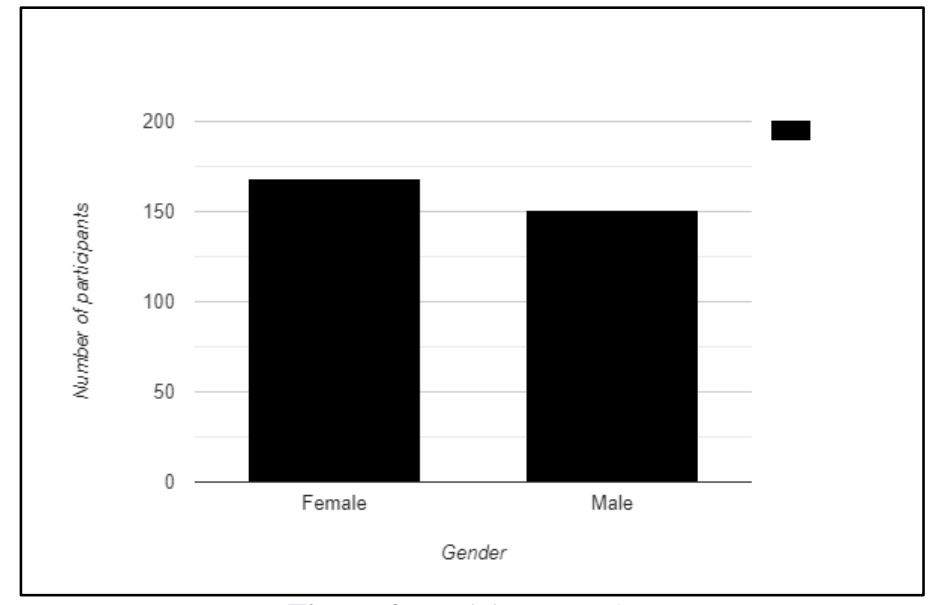

Figure 4: Participant gender

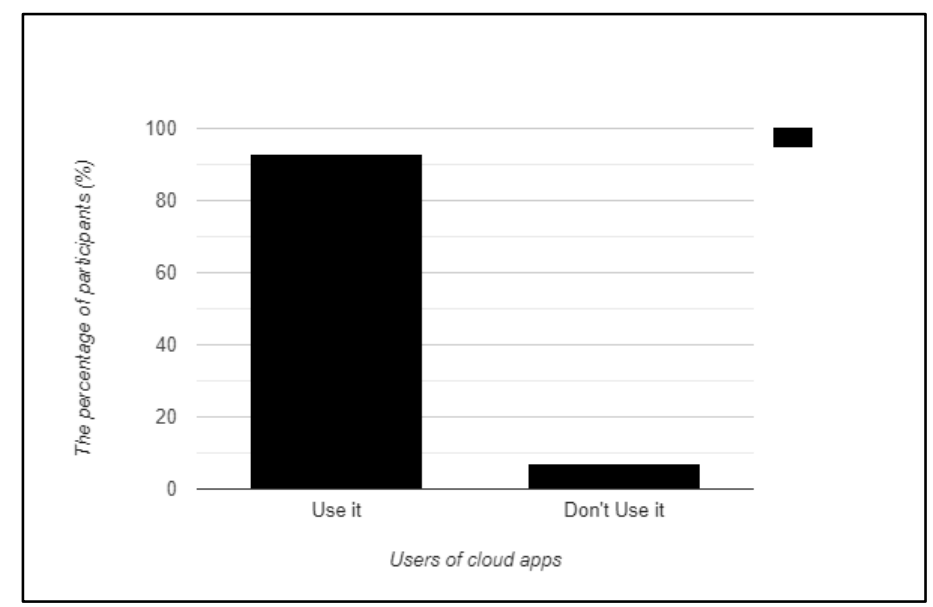

Figure 6: The rate of using cloud computing apps

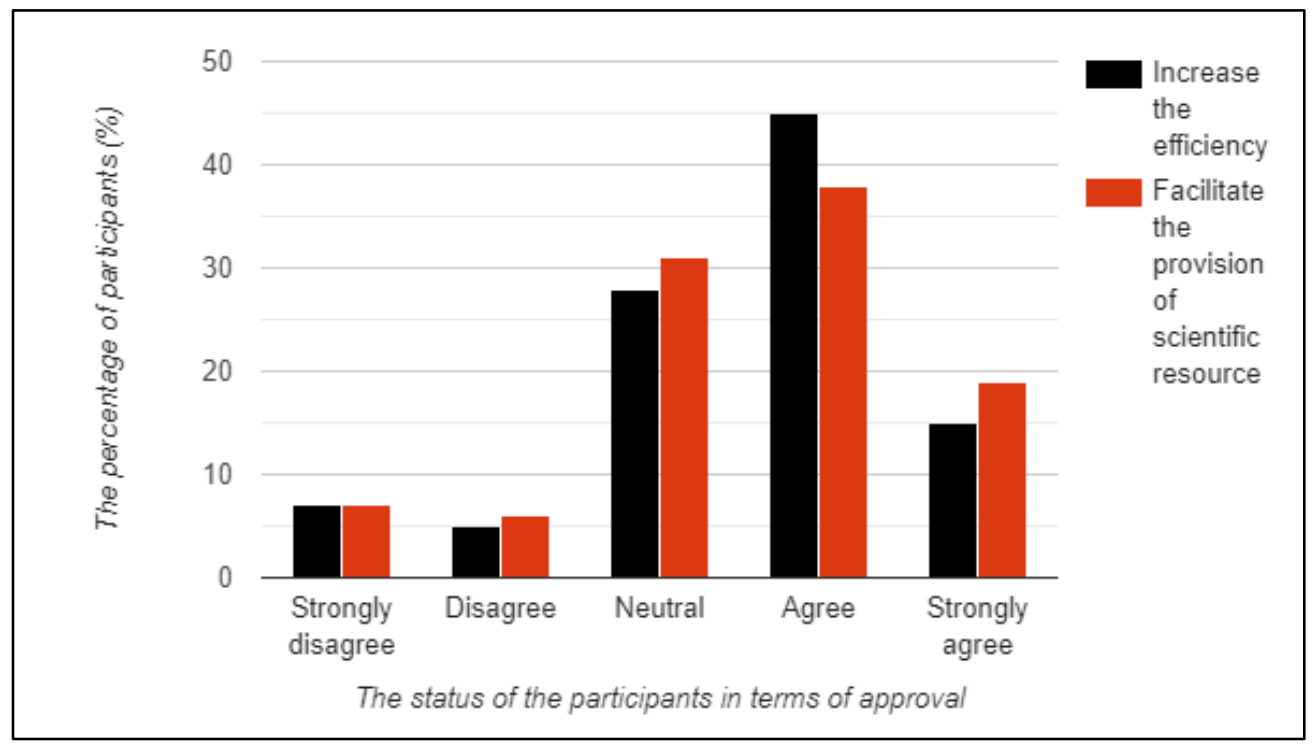

Figure 7: The effect of different hindrances on the adoption of cloud computing 


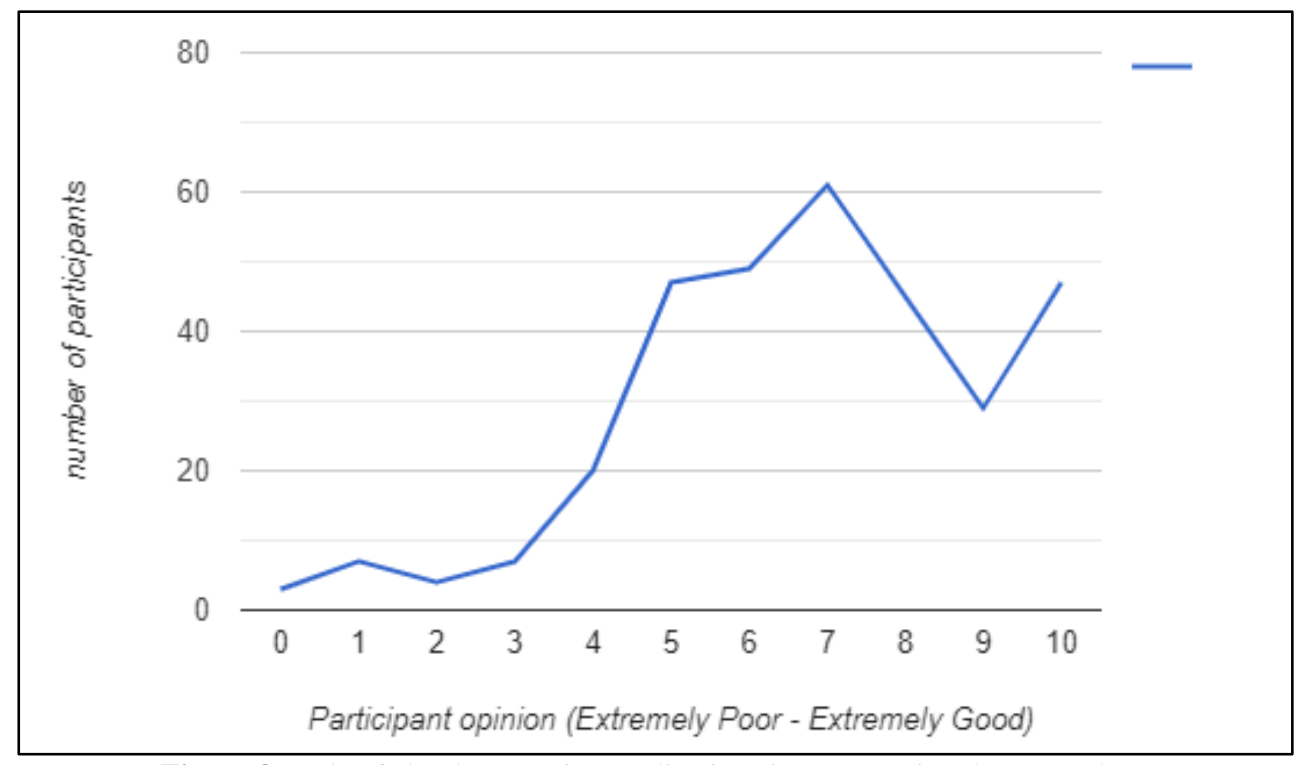

Figure 8: Role of cloud computing applications in encouraging the researchers

\section{Result and discussions}

6. 1 Benefits and Challenges of Cloud Computing from the perception of the university Staffs.

For more than three decades, Iraqi researchers did not trust adopting cloud computing technologies for their research purposes. However, the situation has been changed recently. With the development of educational cloud computing systems, the new cloud applications help the researchers to communicate as well as getting their work done easily in their web browsers especially during COVID-19 pandemic outbreak. On the basis of the test results, the image of the university members who are using the cloud can be obtained. In this part, issues related to the benefits and challenges of using the cloud, have been raised. The benefits are mainly concerned on:

1) Availability

2) Save cost

3) Outsourced development and maintenance

4) Minimal training on the personnel

5) Super-Computing Power

From the perspective of the users, as it is clear in Figure 9, it can be concluding that the main benefit of using the clouds was the ability to access the data from anywhere and by using any portable devices. In the second place was the ability of saving the costs of installing IT infrastructure. On the other hand, concerns about Super-Computing Power and Minimal training on the personnel, cause that a significant number of the university staff use it. In contrast, the ability to get outsourced development and maintenance was another reason that made few number of the participants use the cloud applications for their research purpose. Despite the benefits, there are various hindrances to the adoption of cloud computing in the education system. Many researchers work out to find the main challenges of adopting the cloud computing in the educations fields. In this paper The challenges are mainly concerned on:

- Privacy: since the could computing requires to introduce the platform provider, the protection of information is difficult to keep up,
- Real benefits: The educators should realize the advantages of adopting cloud computing rather than just thinking of its potential.

- Service quality: another reason for not adopting cloud computing in the educational institutions was the service quality. Consequently, without enough guarantee, the higher education organizations shy away from shifting to adopt the cloud computing systems in running their operations.

- Lack of adequate network responsiveness: Most of the institutions cannot adopt cloud computing affectively because of the lack in the internet services,

- Integration: integrating the existing data frameworks of the educational institutes with cloud applications in a quick and financially savvy and simple way.

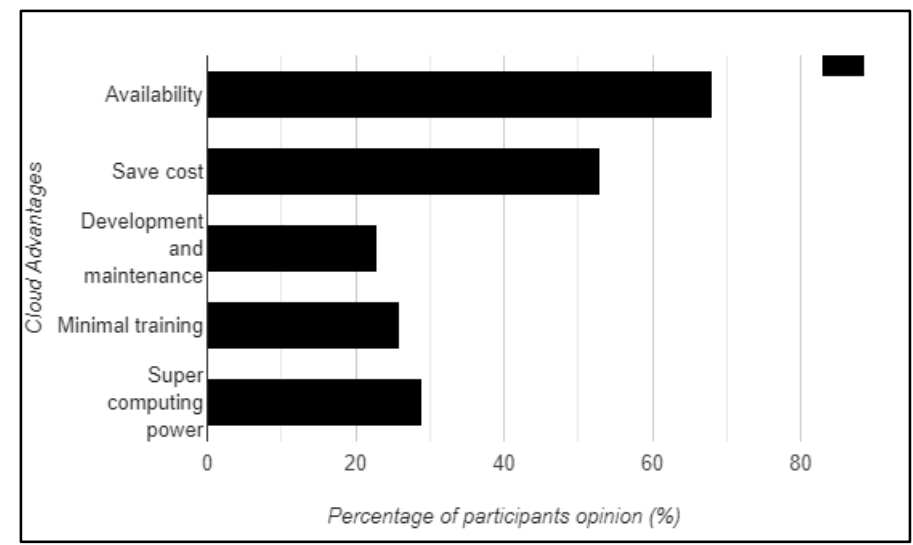

Figure 9: The main benefits of using the clouds

Based on the results, it became obvious that the largest percentage of respondents agree with this, that the privacy and security, lack of adequate network responsiveness and the integration have natural impacts on the adoption of cloud in their institutes during COVID-19 pandemic. However, only about $16 \%$ of the respondents stated that the Real Benefits and Service Quality have very Large effect on the adoption of cloud computing in the educational institutes. See Figure 10. 


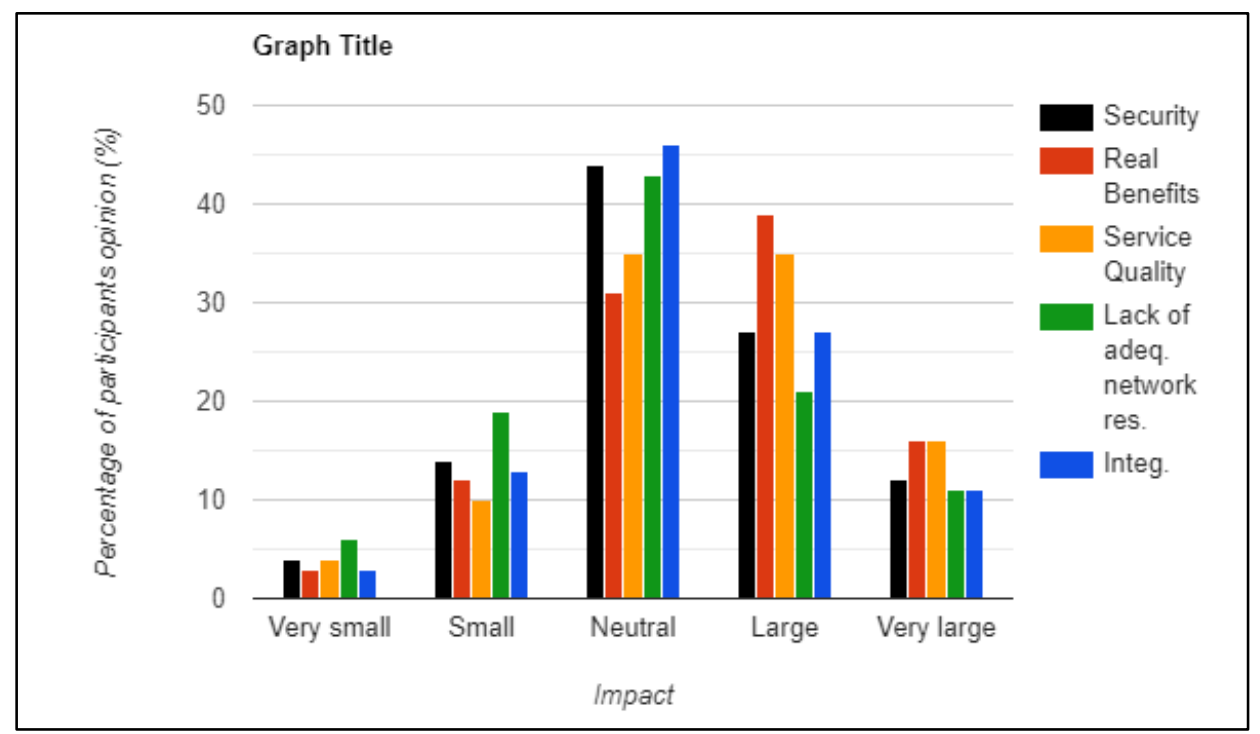

Figure 10: The effect of various hindrances to the adoption of cloud computing in the education system

6. 2 Problems and concerns of adopting the Cloud Computing from the perception of the university Staffs.

In spite of the advantages related to the adoption of cloud computing in higher education fields, there are likewise various problems and concerns which ought to be considered. The most basic problems related to the adoption of cloud computing were represented by:

- Security of data

- Cloud cost management

- Compliance

- Insufficiency of resources and expertise

- Governance

- Performance

- Unauthorized service providers

- Reliability of the technology

- Lack of user control

- Cloud trust issues

Based on the survey, the results show that the security of data represents the major downside that should be considered. Further, the performance and lack of user control make about $24 \%$ of the

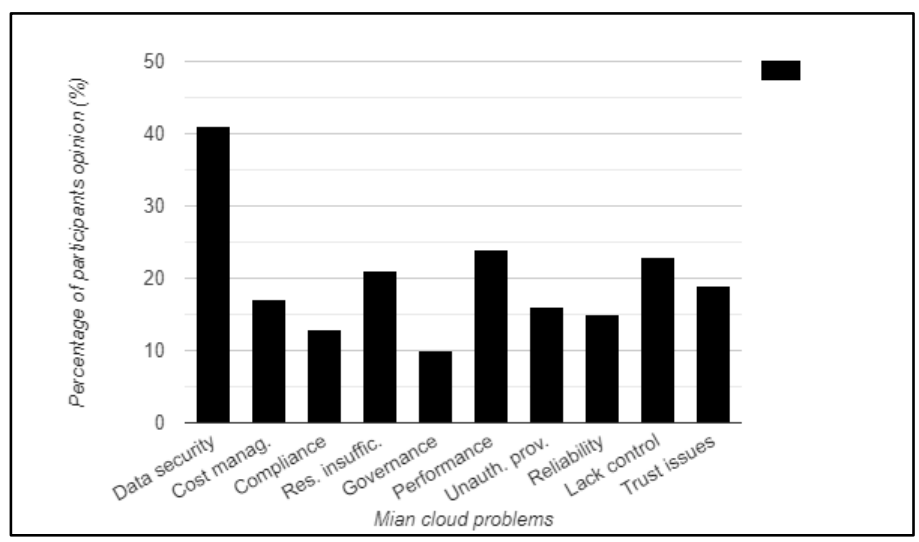

Figure 11: Problems related to the adoption of cloud computing

\section{Conclusion}

Due to the current circumstances of the COVID-19 pandemic, the dependence on cloud computing applications and other technologies has increased significantly. There is no doubt that participant do not use cloud computing applications. However, the most critical cons related to compliance, reliability on new technology, unauthorized service providers, cloud cost management were identified by less than $17 \%$ of the participant as the main problems which should be considered. whereas only about $10 \%$ of the respondents stated that the governance represents the main problem that may face the adoption of cloud computing in the educational institutes. See Figure 11. Despite the problems, there are also substantial performance concerns exist. Moreover, control is another issue confronting $41 \%$ of people utilizing cloud. Furthermore, reliability and confidentiality are likewise another worry of distributed computing, stated by the respondents as shown in Figure 12 . Finally, the obtained results were promising and comparable with many recent researches done in the same field including those have been already mentioned in the literature review section of this paper. In comparison, most of the downsides, that have been mentioned in the previous studies, were not stated as major problems and concerns of adopting cloud computing in Iraqi universities and that was the expected future for the cloud computing systems ${ }^{[7,27]}$.

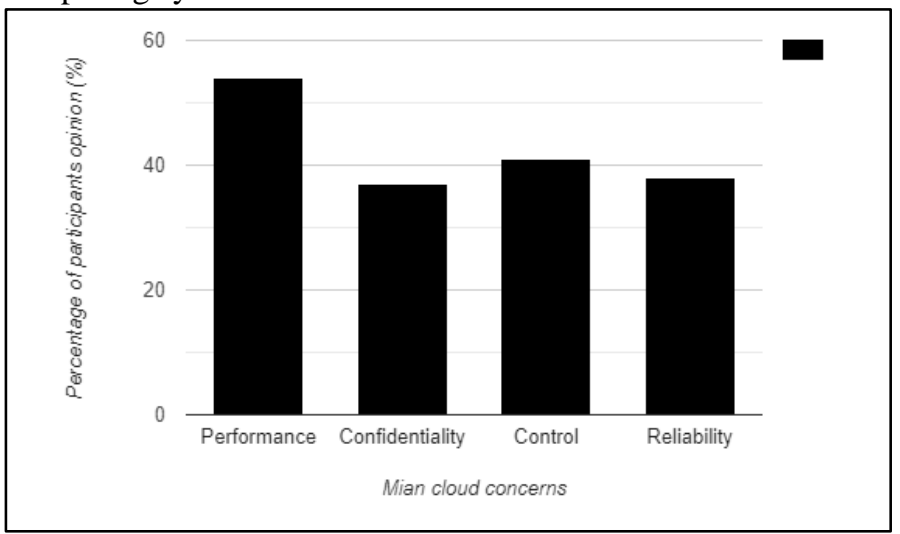

Figure 12: The main Concerns of using cloud computing apps

this pandemic crisis has affected almost all sectors, such as tourism, healthcare, and education. The large increase in data volume during the rapid spread of the COVID-19 pandemic has led to reliance on new mechanisms and technologies in storing 
and using data. In this article, we tried to show the actual impact on the use of cloud computing as an effective technology for use in higher education institutions during that period.

Cloud computing plays a great role in facilitating the work of university staff and improving educational interest in various kinds of higher educational institutions. The adoption of cloud computing applications in Iraqi higher education institutes offers great advantages like: stability, rapid, appropriateness, as well as coetaneous accessibility of low-cost effect in comparison with to other technique by the users of internet.

The obtained results of the present study indicate that $93 \%$ of the academic staff in higher education institutes in Iraq have adopted one of the types of cloud computing. The results also showed that the cloud computing help to increase the efficiency and facilitate the communications among the ranchers as well as facilitating the provision of scientific resources. Moreover, availability and save cost were stated as the most important factors in applying cloud computing especially in developing countries, as they are providing customers with various resources at anytime, anywhere and with any device connected to the Internet. Nevertheless, security, performance, safety, and control problems remained among the biggest problems and concerns facing academic users which can be treated by applying multi-security layers in cloud.

Finally, it is worth to be mentioned that such a research would allow to improve customized technology adoption methods for the investors in public and private higher educational institutions and to recognize the vital issues in this area which can be used for encouraging the researchers in their institutes. As part of future work, the study can be repeated in other countries to compare the significant factors related to usage of cloud computing frameworks in the higher educational sectors.

\section{Conflict of interests}

None.

\section{References}

1. N. Lad, importance of Cloud Computing In Education Sector!, Int. J. Innovative. Res. Sci. Technol., vol. 2, no. 10, pp. 191-194 (2016)

2. Y. A. M. Qasem, R. Abdullah, Y. Y. Jusoh, R. Atan, and S. Asadi, Cloud Computing Adoption in Higher Education Institutions: A Systematic Review, IEEE Access, vol. 7, pp. 63722-63744, doi: 10.1109/ACCESS.2019.2916234 (2019)

3. J. P. Mishra, S. R. Panda, B. Pati, and S. K. Mishra, A novel observation on cloud computing in education, Int. J. Recent Technol. Eng., vol. 8, no. 3, pp. 5262-5274, doi: 10.35940/ijrte.C5910.098319, (2019)

4. S. K. Garg, S. Versteeg, and R. Buyya, A framework for ranking of cloud computing services, Futur. Gener. Comput. Syst., vol. 29, no. 4, pp. 1012-1023, doi: 10.1016/j.future.2012.06.006 (2013)

5. T. Ercan, Effective use of cloud computing in educational institutions, Procedia - Soc. Behav. Sci., vol. 2, no. 2, pp. 938-942, doi: 10.1016/j.sbspro.2010.03.130 (2010)

6. W. Z. Khan, E. Ahmed, S. Hakak, I. Yaqoob, and A. Ahmed, Edge computing: A survey, Futur. Gener. Comput. Syst., vol. 97, pp. 219-235, doi: 10.1016/j.future.2019.02.050 (2019)

7. M. A. Islam, F. Bin Abul Kasem, and S.-U. Zaman Khan, Cloud Computing in Education : Potentials and Challenges for Bangladesh, Int. J. Comput. Sci. Eng. Appl., vol. 7, no. 5, pp. 11-21, doi: 10.5121/ijcsea.2017.7502 (2017)

8. Z. R. Alashhab, M. Anbar, M. M. Singh, Y.-B. Leau, Z. A. Al-Sai, and S. Abu Alhayja'a, Impact of coronavirus pandemic crisis on technologies and cloud computing applications, J. Electron. Sci. Technol., no. May, p. 100059, doi: 10.1016/j.jnlest.2020.100059 (2020)
9. Y. K. Dwivedi et al., Impact of COVID-19 pandemic on information management research and practice: Transforming education, work and life, Int. J. Inf. Manage., vol. 55, no. July, p. 102211, doi: 10.1016/j.ijinfomgt.2020.102211 (2020)

10. A. M. Ahmed and O. W. Allawi, a Review Study on the Adoption of Cloud Computing for Higher Education in Kurdistan Region- Iraq, UHD J. Sci. Technol., vol. 4, no. 1, p. 59, doi: 10.21928/uhdjst.v4n1y2020.pp59-70 (2020)

11. E. A. Ahmed and H. A. Ahmed, A Proposed Model for Education System Using Cloud Computing,2018 3rd Int. Conf. Emerg. Trends Eng. Sci. Technol. ICEEST 2018, no. December 2018, 2019, doi: 10.1109/ICEEST.2018.8643331.

12. R. M. Almajalid, A Survey on the Adoption of Cloud Computing in Education Sector, arXiv, vol. 60, no. 1, pp. 15-25 (2017)

13. A. Srinivasan, Q. M. Abdul, and V. Vijayakumar, Hybrid cloud for educational sector, Procedia Comput. Sci., vol. 50, pp. 37-41, doi: 10.1016/j.procs.2015.04.008 (2015)

14. A. Bouyer and B. Arasteh, The Necessity of Using Cloud Computing in Educational System, Procedia - Social and Behavioral Sciences, vol. 143. pp. 581-585, doi: 10.1016/j.sbspro.2014.07.440 (2014)

15. M. B. Ali, Multiple Perspective of Cloud Computing Adoption Determinants in Higher Education a Systematic Review, Int. J. Cloud Appl. Comput., vol. 9, no. 3, pp. 89-109, doi: 10.4018/ijcac.2019070106 (2019)

16. J. S. J. Rajasingh and J. Reeves Wesley, Step into the cloud or stop with virtualization - The project manager's dialectic dilemma, Procedia Comput. Sci., vol. 172, no. 2019, pp. 1077-1083, doi: 10.1016/j.procs.2020.05.157 (2020).

17. Gomita and T. Manglani, Role of Cloud Computing in Modern Education System, Int. J. Eng. Trends Technol., vol. 50, no. 3, pp. 180-183, doi: 10.14445/22315381/ijettv50p228 (2017)

18. C. Bulla, B. Hunshal, and S. Mehta, Adoption of Cloud Computing in Education System: A Survey, Int. J. Eng. Sci., vol. 6375, no. July, doi: 10.4010/2016.1532 (2016)

19. Alashhab Z, Anbar M, Singh M, Leau Y, Al-Sai Z, Alhayja'a S, Impact of Coronavirus Pandemic Crisis on Technologies and Cloud Computing Applications, Pharmacol. Res., p. 104743, doi: 10.1016/j.jnlest.2020.100059 (2020)

20. N. Sultan, Cloud computing for education: A new dawn?, Int. J. Inf. Manage., vol. 30, no. 2, pp. 109-116, doi: 10.1016/j.jijnfomgt.2009.09.004 (2010)

21. T. Auxsorn, W. Wongthai, T. Porka, and W. Jaiboon, The accuracy measurement of logging systems on different hardware environments in infrastructure as a service cloud, ICIC Express Lett. Part B Appl., vol. 11, no. 5, pp. 427-437, doi: 10.24507/icicelb.11.05.427 (2020)

22. M. Nofan and A. Sakran, The Usage of Cloud Computing in Education, Iraqi $\mathbf{J}$ Comput. Informatics, vol. 42, no. 1, pp. 68-73, doi: 10.25195/ijci.v42i1.87 (2016)

23. N. Sclater, Cloud computing in eductation Policy brief, UNESCO Institute for Information Technologies in Education, [Online]. Available: http://iite.unesco.org (2010)

24. R. M. Almajalid, A Survey on the Adoption of Cloud Computing in Education Sector, arXiv, pp. 1-12 (2017)

25. D. Rani and R. K. Ranjan, A Comparative Study of SaaS , PaaS and IaaS in Cloud Computing, Int. J. Adv. Res. Comput. Sci. Softw. Eng., vol. 4, no. 6, pp. 458-461 (2014)

26. A. Rashid and A. Chaturvedi, Cloud Computing Characteristics and Services A Brief Review, Int. J. Comput. Sci. Eng., vol. 7, no. 2, pp. 421-426, doi: 10.26438/ijcse/v7i2.421426 (2019)

27. A. A. Tashkandi and I. Al-Jabri, Cloud Computing Adoption by Higher Education Institutions in Saudi Arabia: Analysis Based on TOE, 2015 Int. Conf. Cloud Comput. ICCC 2015, doi: 10.1109/CLOUDCOMP.2015.7149634 (2015) 